\title{
Abnormal regulation of cell membrane fluidity in diabetic nephropathy
}

\author{
S.C. Jones, T.H. Thomas, S. M. Marshall \\ Department of Medicine, University of Newcastle upon Tyne, Newcastle upon Tyne, UK
}

\begin{abstract}
Summary An abnormality of the physical properties of the cell membrane may underlie the defect that unites the clinical and biochemical abnormalities found in subjects with diabetic nephropathy. The cell membrane is linked both structurally and functionally with the cytoskeleton. The fluorescence anisotropy, a measure of membrane fluidity, was studied at baseline and after modulation of cytoskeletal proteins by thiol group alkylation with N-ethylmaleimide (NEM). 1,6-diphenyl-1,3,5-hexatriene (DPH) was used to assess anisotropy in the deep hydrophobic regions of the lipid bilayer and trimethylammoniumdiphenylhexatriene (TMA-DPH) was used to assess the superficial, relatively hydrophilic regions. We compared 17 subjects with insulin-dependent diabetes mellitus (IDDM) and nephropathy with 17 control subjects with IDDM and 24 non-diabetic control subjects. Median TMA-DPH anisotropy (0.271 (0.239-0.332) vs $0.269(0.258-0.281)$ vs $0.275(0.246-$ $0.287)$ ) and DPH anisotropy (0.221 (0.193-0.261) vs $0.227(0.197-0.253)$ vs $0.226(0.193-0.245))$ were similar in erythrocytes from the three groups. However
\end{abstract}

after alkylation of protein thiol groups with NEM clear differences emerged. In the control subjects with and without IDDM there was a significant fall in TMA-DPH anisotropy compared to the subjects with diabetic nephropathy in whom the addition of NEM had no effect ( $\triangle$ TMA-DPH anisotropy -0.005 $(-0.020-+0.006)$ vs $-0.005(-0.011-+0.016)$ vs + $0.002(-0.010-+0.008) p<0.001)$. This finding was confirmed when the deep regions of the lipid bilayer were assessed using DPH ( $\triangle \mathrm{DPH}$ anisotropy -0.017 $(-0.029--0.007$.$) vs -0.015(-0.029-+0.001)$ vs + $0.003(-0.021-+0.018) p<0.001)$. We conclude that cytoskeletal modulation of the physical properties of the cell membrane lipids by proteins is abnormal in subjects with diabetic nephropathy. Such an abnormality could explain some of the clinical and metabolic abnormalities found in this condition. [Diabetologia (1998) 41: 337-342]

Keywords Diabetic nephropathy, fluidity, anisotropy, $\mathrm{N}$-ethylmaleimide, erythrocyte, insulin-dependent diabetes mellitus.
Diabetic nephropathy is a condition that appears to arise from an interaction between poor glycaemic control [1] and inherited factors [2]. Insulin-depen-

Received: 10 July 1997 and in revised form: 23 October 1997

Corresponding author: Dr. S.C. Jones, Department of Medicine, The Medical School, Framlington Place, Newcastle Upon Tyne, NE2 4HH, UK

Abbreviations: IDDM, Insulin-dependent diabetes mellitus; DPH, 1,6-diphenyl-1,3,5-hexatriene; TMA-DPH, trimethylammonium-diphenylhexatriene; NEM, N-ethylmaleimide; Na-Li CT, sodium-lithium countertransport; UAER, urinary albumin excretion rate; ACE, angiotensin converting enzyme. dent diabetic (IDDM) patients with nephropathy are characteristically hypertensive, have diabetic retinopathy, are relatively insulin resistant and have raised levels of serum triglycerides [3-6]. In addition, rates of activity of cell membrane cation transporters, such as the sodium-hydrogen exchanger [7,8] and the sodium-lithium countertransporter ( $\mathrm{Na}-\mathrm{Li}$ CT) [9-11] are increased in patients with diabetic kidney disease. The very close association of these abnormalities suggests a common aetiology. Na-Li CT has a large inherited component [12] and, although it appears to have no pathophysiological role, may be an inherited marker for an abnormality 
in the cell membrane which could explain the clinical and biochemical features of diabetic nephropathy [13].

The physical properties of the lipid bilayer of the cell membrane can be assessed by the measurement of the fluorescence anisotropy of 1,6-diphenyl-1,3,5hexatriene (DPH) and trimethylammonium-diphenylhexatriene (TMA - DPH) $[14,15]$. DPH is a relatively hydrophobic molecule and positions itself in the deep hydrophobic regions of the lipid bilayer. TMA-DPH is more hydrophilic and therefore positions itself in the more superficial regions of the cell membrane. The fluidity of the regions in which the dyes are situated affects their rate of rotation and hence the degree of depolarisation of fluorescent light. The anisotropy value is a quantitative expression of this effect and may be regarded as having an inverse relationship with the fluidity of the lipid bilayer.

In a previous study anisotropy assessed in ghosted erythrocytes appeared similar in subjects with and without diabetic nephropathy [16], though it correlated with $\mathrm{Na}-\mathrm{Li} \mathrm{CT}$ activity, the latter measured in whole intact erythrocytes. It has since been demonstrated that the process of ghosting disrupts the lipid bilayer, reducing anisotropy, possibly by an effect on cell membrane modulating cytoskeletal structures [17]. This effect can be mimicked by thiol group alkylation with N-ethylmaleimide (NEM) which alkylates a number of proteins including several within the cytoskeleton $[18,19]$, which is itself a part of a structural and functional unit with the cell membrane.

The occurrence of hypertension, raised triglyceride levels, insulin resistance and ion transporter abnormalities in diabetic nephropathy may be due to a common underlying mechanism, specifically an abnormality of thiol containing cytoskeletal proteins which may be manifest as an abnormality in cell membrane fluidity. However, neither the anisotropy in intact erythrocytes, nor the effect of thiol group alkylation with NEM on anisotropy, have been described in diabetic nephropathy.

The aims of the present study were therefore to: 1. Assess fluorescence anisotropy in intact erythrocytes from patients with diabetic nephropathy, IDDM control subjects and non-diabetic control subjects.

2. Study the role of thiol proteins on membrane state by observing the effects of alkylation with NEM on anisotropy.

\section{Subjects and methods}

Patients. Seventeen subjects with IDDM (initial presentation with weight loss and ketosis, at age less than 35 years) and diabetic nephropathy were studied. A median urinary albumin excretion rate (UAER) from three timed overnight collec- tions of over $20 \mu \mathrm{g} \mathrm{min} \mathrm{m}^{-1}$ (inter assay coefficient of variation at $4.95 \mathrm{mg} \mathrm{l}^{-1}, 3.6 \%$ ) was used to define the presence of diabetic nephropathy. Subjects with a UAER in the microalbuminuric range $\left(20-200 \mu \mathrm{g} \mathrm{min}{ }^{-1}\right)$ were only included if the median of a further three collections, within 3-6 months, confirmed the presence of raised UAER. Patients were excluded if serum creatinine exceeded $150 \mu \mathrm{mol} \mathrm{l}^{-1}$ to avoid possible confounding effects of uraemia on anisotropy. A control group of 17 subjects with IDDM and normal albumin excretion (UAER $<20 \mu \mathrm{g} \mathrm{min}{ }^{-1}$ ) of similar age and sex to the subjects with diabetic nephropathy was studied. To ensure that they were unlikely to develop nephropathy in the future, duration of diabetes was more than 20 years in the diabetic control subjects. A second control group of 24 non-diabetic subjects was also studied. These individuals had no personal history of, or first degree relative with diabetes (insulin-dependent or non-insulin-dependent), hypertension or dyslipidaemia. Nine of the subjects with IDDM and nephropathy were taking an angiotensin converting enzyme (ACE) inhibitor, 4 in combination with a diuretic. A further 3 subjects received a calcium channel blocking agent and one lipid lowering medication. None of the IDDM control subjects were taking medication with the exception of insulin. None of the nondiabetic control subjects was taking medication. Ethical approval for this study was granted by the Newcastle Health Authority/Newcastle University Joint Ethical Committee, and all subjects gave their informed consent.

Evaluation of subjects. Blood pressure (Korotkoff phases 1 and 5) was measured in the sitting position after $10 \mathrm{~min}$ rest, and recorded as the mean of three measurements taken over a $10 \mathrm{~min}$ period. Hypertension was defined as treatment with anti-hypertensive medication and or mean blood pressure greater than 140/90 mmHg. All blood samples were taken after an overnight fast of at least $10 \mathrm{~h}$. All medication, other than insulin, was stopped for the $24 \mathrm{~h}$ preceding the study. Glycated haemoglobin was assessed using HPLC (Biorad, normal range up to $6.1 \%$; Biorad Hemel Hempstead, Herts, UK). Fasting serum triglycerides, total cholesterol and creatinine were determined using enzymatic methods (DAX multichannel analyser, Bayer, Berks, UK).

Anisotropy measurements. The details of the assay used to measure anisotropy are described in detail in a previous report from our group [17]. Briefly erythrocytes were first washed with isotonic phosphate buffered saline and fluorescence anisotropy was measured in a $3 \mathrm{ml}$ aliquot of a $0.1 \%$ packed cell volume suspension of cells. TMA-DPH anisotropy was measured after 5 min incubation with a $2 \times 10^{-6} \mathrm{~mol} \mathrm{l}^{-1}$ solution. DPH anisotropy (concentration $2 \times 10^{-6} \mathrm{~mol} \mathrm{l}^{-1}$ ) was measured after incubation at $37^{\circ} \mathrm{C}$ for $45 \mathrm{~min}$ in the dark. Anisotropy values were measured with a Perkin-Elmer LS $50 \mathrm{~B}$ luminescence spectrometer (Perkin-Elmer, Beaconsfield, Bucks, UK) at $37^{\circ} \mathrm{C}$ with excitation and emission wavelengths of 360 and $430 \mathrm{~nm}$ respectively and slit widths of $10 \mathrm{~nm}$. Anisotropy (A) was calculated according to the equations:

$\mathrm{A}=\frac{\mathrm{I}_{\mathrm{vv}}-\left[\mathrm{G} \times \mathrm{I}_{\mathrm{vh}}\right]}{\mathrm{I}_{\mathrm{vv}}+\left[2 \mathrm{G} \times \mathrm{I}_{\mathrm{vh}}\right]}$

$\mathrm{G}=\frac{\mathrm{I}_{\mathrm{hv}}}{\mathrm{I}_{\mathrm{hh}}}$

where $I_{v v}$ and $I_{v h}$ are the intensities with the excitation in the vertical (v) position and the analyser in the vertical (v) or horizontal (h) position, respectively. $G$ is the correction for the optical system and was determined before each measurement of anisotropy. 
Table 1. Clinical characteristics of subjects

\begin{tabular}{|c|c|c|c|}
\hline & $\begin{array}{l}\text { Non-diabetic } \\
\text { control subjects } \\
(n=24)\end{array}$ & $\begin{array}{l}\text { IDDM control } \\
\text { subjects } \\
(n=17)\end{array}$ & $\begin{array}{l}\text { Subjects with IDDM } \\
\text { and nephropathy } \\
(n=17)\end{array}$ \\
\hline Age (years) & $40(37-43)$ & $46(43-49)$ & $44(39-49)$ \\
\hline Sex (male/female) & $14: 10$ & $10: 7$ & $12: 5$ \\
\hline Duration of diabetes (years) & & $31(27-35)$ & $23^{\mathrm{a}}(20-26)$ \\
\hline Urinary albumin excretion rate $\left(\mu \mathrm{g} \min ^{-1}\right)$ & $4.2(2.4-10.7)$ & $4.6(2.6-12.2)$ & $98.1^{\mathrm{b}}(29.0-3400)$ \\
\hline Hypertension (Yes : No) & $0: 24$ & $0: 17$ & $12: 5$ \\
\hline Creatinine $\left(\mu \mathrm{mol} 1^{-1}\right)$ & $81(72-98)$ & $86(67-109)$ & $85(67-107)$ \\
\hline Fasting triglycerides $\left(\mathrm{mmol} \mathrm{l}^{-1}\right)$ & $1.1(0.3-2.2)$ & $0.9(0.4-2.2)$ & $1.5(0.7-6.9)^{\mathrm{b}}$ \\
\hline Total cholesterol $\left(\mathrm{mmol} \mathrm{l}^{-1}\right)$ & $4.9(4.5-5.3)$ & $5.3(4.8-5.8)$ & $5.9(5.3-6.5)$ \\
\hline $\mathrm{HbA}_{1 \mathrm{c}}(\%)$ & - & $7.3(6.7-7.9)$ & $8.1(7.3-8.9)$ \\
\hline Insulin dose (IU kg-1) & & $0.63(0.54-0.72)$ & $0.83^{\mathrm{a}}(0.75-0.91)$ \\
\hline
\end{tabular}

Continuous variables described as mean with $95 \%$ confidence intervals. Fasting triglycerides, urinary albumin excretion rate and creatinine described as median with range.
${ }^{a} p<0.05$, subjects with diabetic nephropathy vs control subjects with IDDM;

${ }^{\mathrm{b}} p<0.001$, subjects with diabetic nephropathy vs both control groups

Table 2. Comparison of anisotropy at baseline and after thiol group alkylation with N-ethylmaleimide

\begin{tabular}{llcc}
\hline & $\begin{array}{l}\text { Normal control } \\
\text { subjects } \\
(n=24)\end{array}$ & $\begin{array}{l}\text { Diabetic control } \\
\text { subjects } \\
(n=17)\end{array}$ & $\begin{array}{l}\text { Subjects with } \\
\text { IDDM and } \\
\text { nephropathy } \\
(n=17)\end{array}$ \\
\hline TMA anisotropy & $0.275(0.246-0.287)$ & $0.269(0.258-0.281)$ & $0.271(0.239-0.332)$ \\
TMA anisotropy after NEM & $0.271(0.240-0.278)$ & $0.266^{\mathrm{c}}(0.248-0.273)$ & $0.273(0.237-0.331)$ \\
$\Delta$ TMA anisotropy & $-0.005(-0.011-+0.016)$ & $-0.005(-0.020-+0.006)$ & $+0.002^{\mathrm{b}}(-0.010-+0.008)$ \\
DPH anisotropy & $0.226(0.193-0.245)$ & $0.227(0.197-0.253)$ & $0.221(0.193-0.261)$ \\
DPA anisotropy after NEM & $0.211(0.173-0.237)$ & $0.211(0.182-0.230)$ & $0.220^{\mathrm{a}}(0.198-0.267)$ \\
$\Delta$ DPH anisotropy & $-0.015(-0.029-+0.001)$ & $-0.017(-0.029--0.007)$ & $+0.003^{\mathrm{b}}(-0.021-+0.018)$ \\
\hline All variables described as median (range) & & ${ }^{\mathrm{b}} p<0.001$ subjects with nephropathy vs both control groups; \\
a $p<0.05$ subjects with nephropathy vs both control groups; & ${ }^{\mathrm{c} p} p<0.05$ IDDM control subjects vs subjects with nephropathy
\end{tabular}

Statistical methods. Differences between the three groups were assessed by analysis of variance (ANOVA). If significant differences were found Student's $t$-test (unpaired) was used for comparison between individual groups with correction for multiple testing. Data that are not normally distributed, including anisotropy values, were analysed with the KruskallWallis test of variance and Mann-Whitney test.

\section{Results}

The three groups were similar with respect to age, sex and serum creatinine (Table 1). However, because of selection criteria, the diabetic control subjects had a significantly longer duration of diabetes than the subjects with diabetic nephropathy. The two groups of diabetic subjects were similar with respect to $\mathrm{HbA}_{1 \mathrm{c}}$ but the subjects with nephropathy were more likely to be hypertensive and had higher triglyceride levels. In addition insulin dose per kilogram, a surrogate for insulin resistance, was significantly higher in subjects with diabetic nephropathy.
Anisotropy values in native erythrocytes assessed using DPH and TMA-DPH were similar in the three groups (Table 2 and Fig. $1 \mathrm{a}$ and $\mathrm{b}$ ). After thiol group alkylation using NEM, Median TMA-DPH anisotropy was significantly lower in control subjects with IDDM compared to subjects with diabetic nephropathy (Table 2 and Fig. $1 \mathrm{a}$ ). The change in TMA-DPH after thiol group alkylation was significant in the two control groups (Fig. 2a). In the subjects with diabetic nephropathy the addition of NEM resulted in no statistically significant change in TMA-DPH anisotropy compared to the baseline value and as a result the change in TMA-DPH anisotropy in the nephropathy group was significantly less than in the two control groups.

After NEM, DPH anisotropy was significantly decreased in the two control groups (Table 2 Fig. 2 b) but not in subjects with diabetic nephropathy. As a result median DPH anisotropy was significantly higher in the subjects with diabetic nephropathy after thiol group alkylation than in both control groups (Fig. 1b). 


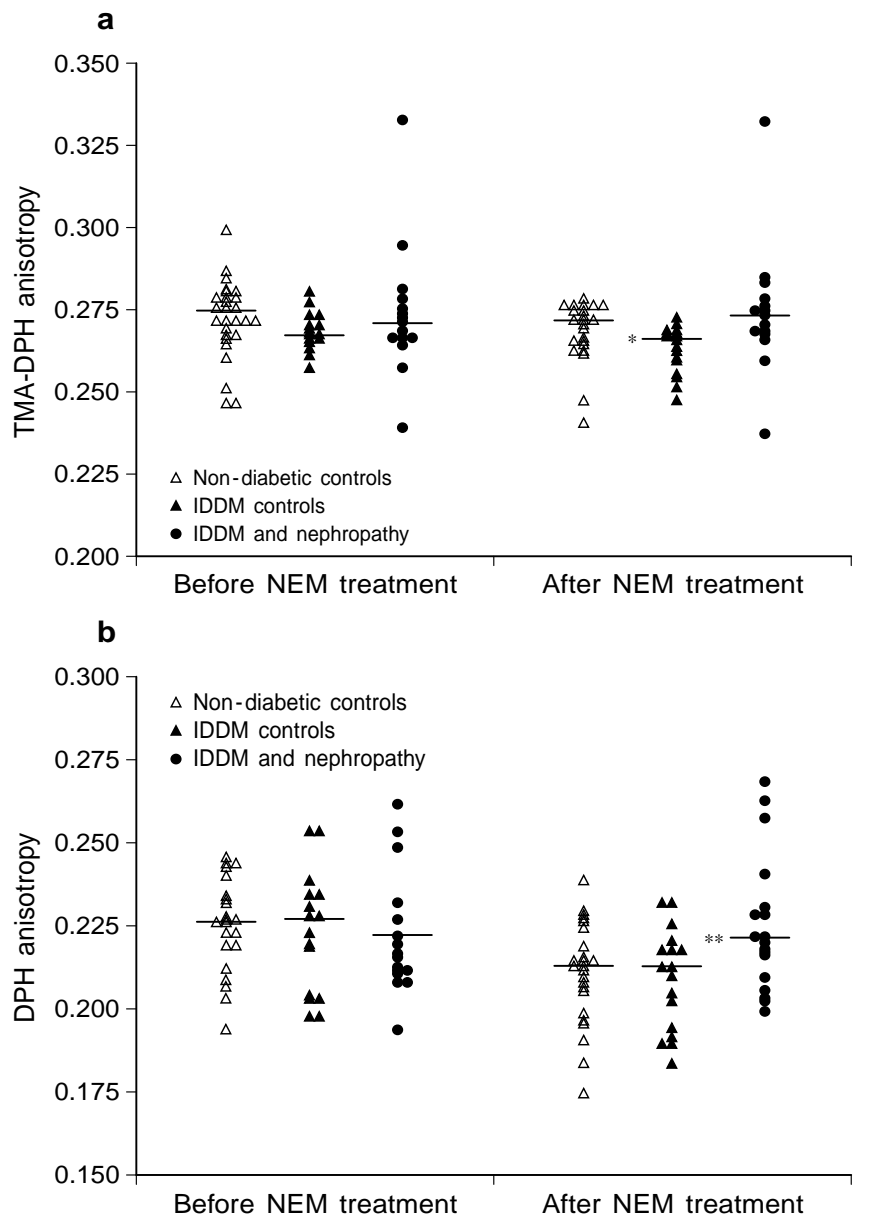

Fig. 1a. TMA-DPH fluorescence anisotropy at baseline and after thiol group alkylation with NEM. Median value - . $* p<$ 0.05 , IDDM control subjects vs subjects with diabetic nephropathy b. DPH fluorescence anisotropy at baseline and after thiol group alkylation with NEM. Median value - ${ }^{* *} p<0.05$, subjects with nephropathy vs both control groups

There was no significant correlation between log transformed anisotropy values and $\mathrm{HbA}_{1 \mathrm{c}}$ and $\log$ transformed serum triglycerides, when either baseline values or changes after thiol group alkylation with N-ethylmaleimide were considered. Half of the subjects with diabetic nephropathy were taking an ACE inhibitor but there were no significant differences in anisotropy values between those who were and were not receiving such treatment.

\section{Discussion}

This study indicates that the baseline fluorescence anisotropy in intact erythrocytes is similar in subjects with diabetic nephropathy and control subjects with and without IDDM. This was the case when both deep and superficial levels of the lipid bilayer were assessed with DPH and TMA-DPH, respectively,
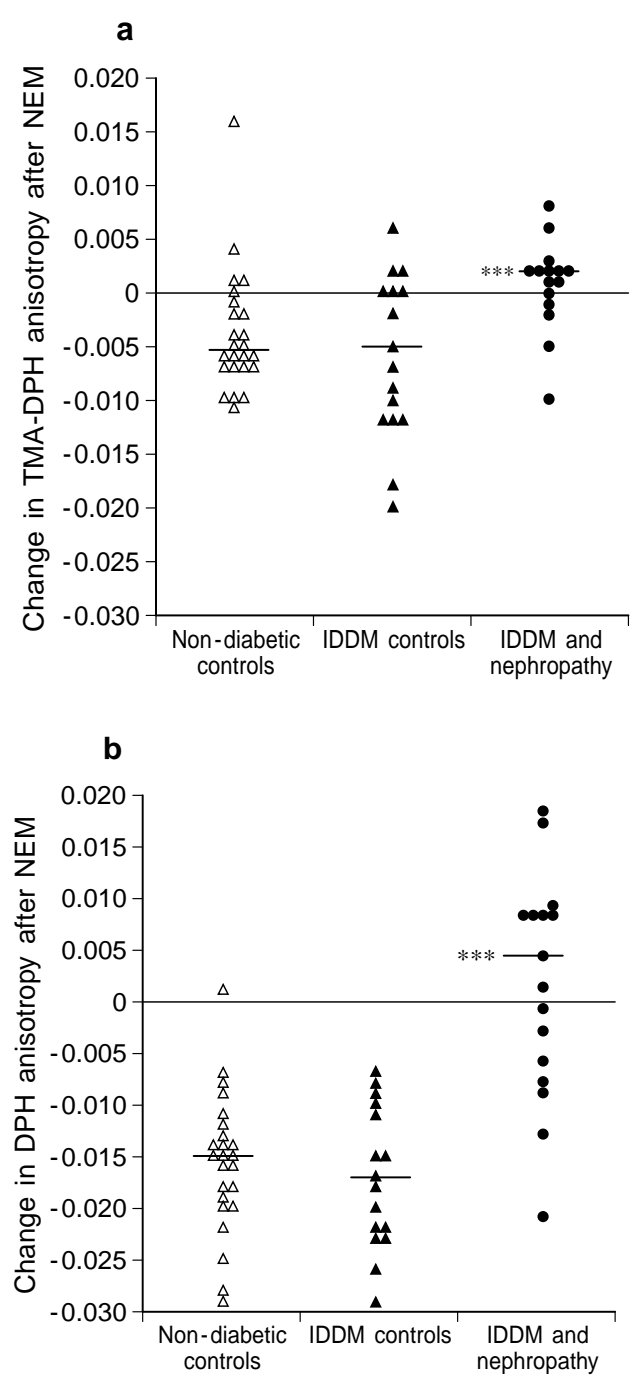

Fig. 2a, b. Change in TMA-DPH (a) and DPH (b) fluorescence anisotropy after thiol group alkylation with NEM. $* * * p<.001$, subjects with nephropathy vs both control groups

and indicates that the steady-state physical properties of the lipid bilayer, such as fluidity, are similar in the three groups.

Modulation of fluorescence anisotropy by thiol group alkylation using N-ethylmaleimide is abnormal in subjects with diabetic nephropathy. This is the case when anisotropy is assessed in both the deep and superficial layers of the cell membrane. Although the reduction in anisotropy is small in percentage terms, this change in the physical properties of the lipid bilayer may result in major alterations in function.

NEM alters the association properties of at least two cytoskeleton proteins that are likely to influence membrane fluidity $[18,19]$. It appears that the thiol protein or proteins involved in this effect also modulate $\mathrm{Na}-\mathrm{Li}$ CT kinetics [20] and we have recently demonstrated that this modulation is abnormal in patients with diabetic nephropathy [21]. As Na-Li CT 
activity has a large inherited component it has been suggested that increased activity represents an inherited marker for the development of diabetic nephropathy [13]. An inherited abnormality in a modulating cytoskeleton protein could therefore underlie many of the abnormalities found in subjects with diabetic nephropathy. For example both insulin resistance [5] and Na-Li CT activity [9-11] are abnormal in subjects with diabetic nephropathy. Insulin resistance may be related to cell membrane fluidity (fluorescence anisotropy) [22] and Na-Li CT abnormalities are due to an NEM sensitive thiol group containing protein within the cell cytoskeleton-cell membrane complex $[20,21]$.

There are a number of ways in which the apparent paradox between abnormal regulation and yet similar baseline anisotropy can be explained. Firstly, an abnormality of a cytoskeletal modulating protein may result in local membrane effects which are beyond the sensitivity of current techniques to detect. $\mathrm{Na}-\mathrm{Li} \mathrm{CT}$ activity is reduced by around $60 \%$ when NEM is added, but if abnormal regulation is isolated to the physical properties of the lipid bilayer in the immediate area of the cell membrane transporter these changes may not be detected when anisotropy of the whole lipid bilayer is studied. However, the fact that differences can be observed when N-ethylmaleimide is added suggests that this hypothesis is unlikely.

Secondly, there may be compensatory changes in the lipid bilayer which interacts in a dynamic relationship with membrane proteins and cytoskeletal elements. As membrane modulating proteins are abnormal in patients with nephropathy and yet baseline anisotropy is unaffected, the composition of the membrane (proportion of cholesterol which increases rigidity, compared to phospholipid, which increases fluidity) may compensate. This would leave global measures of the physical properties of the cell membrane such as fluidity (anisotropy) unchanged but may have important effects on the function of cell membrane proteins. Thus, lipid abnormalities in this condition, including abnormal membrane lipid composition, may represent secondary compensations rather than primary abnormalities.

There are few previous studies with which to compare our results. However in one such study in which anisotropy was assessed using erythrocyte ghosts [16], anisotropy was also similar in subjects with diabetic nephropathy compared with diabetic control subjects. In that study the anisotropy values reported were lower than in intact cells, with DPH anisotropy around $6 \%$ lower and TMA-DPH anisotropy around $15 \%$ lower, presumably due to the ghosting process. The anisotropy values we have obtained among control subjects in intact erythrocytes are similar to those found in control subjects in other studies [23]. Our data has relied on assessment of the erythrocyte membrane and it would be interesting to study other cell lines.

This study confirms that anisotropy, reflecting cell membrane fluidity, is similar in subjects with diabetic nephropathy and control subjects with and without IDDM. However, regulation of anisotropy by a protein within the cytoskeleton is abnormal in subjects with nephropathy. This may go some way to explaining the cell membrane defect that underlies diabetic kidney disease and could link the many clinical and metabolic abnormalities found in this condition.

Acknowledgements. This work was partly funded by The Northern Counties Kidney Research Fund. S. C. Jones is a recipient of a Northern Region Health Authority Research Training Fellowship.

\section{References}

1. The Diabetes Control and Complications (DCCT) Research Group (1995) Effect of intensive therapy on the development and progression of diabetic nephropathy in the Diabetes Control and Complications Trial. Kidney Int 47: 1703-1720

2. Quinn M, Angelico MC, Warram JH, Krolewski AS (1996) Familial factors determine the development of diabetic nephropathy in patients with IDDM. Diabetologia 39: 940-945

3. Wiseman M, Viberti GC, MacIntosh D, Jarrett RJ, Keen H (1981) Glycaemia, arterial pressure and microalbuminuria in type 1 (insulin-dependent) diabetes mellitus. Diabetologia 26: 401-405

4. Kofoed-Enevoldsen A, Jensen T, Borch-Johnsen K, Deckert T (1987) Incidence of diabetic retinopathy in type 1 (insulin dependent) diabetes: Association with clinical nephropathy. J Diabetic Complications 3: 96-99

5. Yip J, Mattock MB, Morocutti A, Sethi M, Trevisan R, Viberti GC (1993) Insulin resistance in insulin-dependent diabetic patients with microalbuminuria. Lancet 342: 883-887

6. Jensen T, Stender S, Deckert T (1988) Abnormalities in plasma concentrations of lipoproteins and fibrinogen in type 1 (insulin-dependent) diabetic patients with increased urinary albumin excretion. Diabetologia 31: 142-145

7. Davies JE, Ng LL, Kofoed-Enevoldsen, Li LK, Earle, KE, Trevisan R, Viberti GC (1992) Intracellular $\mathrm{pH}$ and $\mathrm{Na}^{+} /$ $\mathrm{H}^{+}$antiport activity of cultured skin fibroblasts from diabetics. Kidney Int 42: 1184-1190

8. Trevisan R, Lai LK, Messent J, Tariq T, Earle K, Walker JD, Viberti GC (1992) $\mathrm{Na}^{+} / \mathrm{H}^{+}$antiport activity and cell growth in cultured skin fibroblasts of IDDM patients with nephropathy. Diabetes 41: 1239-1246

9. Mangili R, Bending JJ, Scott G, Li LK, Gupta A, Viberti GC (1988) Increased sodium-lithium countertransport activity in red cells of patients with insulin-dependent diabetes and nephropathy. N Engl J Med 318: 146-150

10. Jones SL, Trevisan R, Tariq T et al (1990) Sodium-lithium countertransport activity is increased in microalbuminuric diabetics. Hypertension 19: 570-575

11. Rutherford PA, Thomas TH, Carr SJ, Taylor R, Wilkinson R (1992) Changes in erythrocyte sodium-lithium countertransport kinetics in diabetic nephropathy. Clin Sci 82: 301-307 
12. Hasstedt SJ, Wu LL, Ash KO, Kuida H, Williams R (1988) Hypertension and sodium-lithium countertransport in Utah pedigrees: evidence for major locus inheritance. Am J Hum Genet 43: 14-22

13. Rutherford PA, Thomas TH, Wilkinson R (1992) Erythrocyte sodium-lithium countertransport: clinically useful, pathophysiologically instructive or just phenomenology? Clin Sci 82: 341-352

14 Donner M, Muller S, Stoltz JFG (1990) Fluorescence depolarisation method in the study of dynamic properties of blood cells. Biorheology 27:367-374

15. Schachter D, Cogan U, Abbott RE (1982) Asymmetry of lipid dynamics in human erythrocyte membranes studied with permanent fluorophores. Biochemistry 21: 2146-2150

16. Dowd A, Thomas TH, Taylor R, Wilkinson R (1994) Erythrocyte sodium-lithium countertransport is related to membrane fluidity in IDDM patients. Diabetologia 37: 394-400

17. Tong P, Thomas TH, Wilkinson R (1994) Membrane fluidity is different in intact erythrocytes and ghost membranes. Biochem Med Metab Biol 52: 132-135
18. Bennett V (1978) Purification of an active proteolytic fragment of the membrane attachment site for human erythrocyte spectrin. J Biol Chem 253: 2292-2299

19. Bennett V (1985) The membrane skeleton of human erythrocytes and its implications for more complex cells. Ann Rev Biochem 54: 273-304

20. Thomas TH, Rutherford PA, West IC, Wilkinson R (1995) Sulphydryl group control of sodium-lithium countertransport kinetics: a membrane protein control abnormality in essential hypertension. Eur J Clin Invest 25: 235-240

21. Jones SC, Thomas TH, Marshall SM (1997) Thiol group modulation of sodium-lithium countertransport kinetics in diabetic nephropathy. Diabetologia 40: 1079-1084

22. Tong P, Thomas T, Berrish T et al. (1995) Cell membrane dynamics and insulin resistance in non-insulin dependent diabetes mellitus. Lancet 345: 357-358

23. Vareesangthip K, Thomas TH, Tong P, Wilkinson R (1996) Erythrocyte membrane fluidity in adult polycystic disease:difference between intact cells and ghost membranes. Eur J Clin Invest 26: 171-173 